\title{
"SANTO DE CASA NÃO FAZ MILAGRE": ANÁLISE ERGONÔMICA EM LABORATÓRIO NO CAMPUSLAR-UFS
}

\author{
COSTA, Pedro de Barros Nunes (1); \\ FONTES, Anna Beatriz da Silva (2); \\ MODESTO, Érica Andrade (3); \\ SILVA, Larissa Scarano P. M. da (4)
}

(1) Universidade Federal de Sergipe, Graduando em Arquitetura e Urbanismo

$$
\text { e-mail:pbnc16@gmail.com }
$$

(2) Universidade Federal de Sergipe, Graduanda em Arquitetura e Urbanismo

$$
\text { e-mail:abeatrizfontes123@gmail.com }
$$

(3) Universidade Federal de Sergipe, Graduanda em Arquitetura e Urbanismo e-mail: ericaandrademodesto@gmail.com

(4) Universidade Federal de Sergipe, Docente de Arquitetura e Urbanismo; Universidade Federal da Bahia, Doutoranda em Arquitetura e Urbanismo

e-mail: larissascarano@hotmail.com

\begin{abstract}
RESUMO
O presente trabalho consiste em uma análise ergonômica de uma sala de Informática, localizada no Campus da Universidade Federal de Sergipe, em Laranjeiras, na busca de compreender a importância da ergonomia no ambiente do trabalho e estudo. Para tal, utilizou-se de medições através de instrumentos específicos, bem como ação metodológica a partir da aplicação de questionários com estudantes que utilizam ou já utilizaram o laboratório. Através das análises e dos resultados obtidos foi possível diagnosticar os principais problemas do respectivo laboratório de informática no tocante à ergonomia e traçar diretrizes para solucionar tais problemas.
\end{abstract}

Palavras chave: laboratório de informática; ergonomia; saúde no trabalho.

\begin{abstract}
The present paper consists in an ergonomic analysis of a computer laboratory, located in the campus of the Universidade Federal de Sergipe, at Laranjeiras, aiming to comprehend the importance of ergonomics in the working and studying environments. For such matters, measures were made using specific devices, as well as methodological action starting with the application of questionnaires with students who use or have previously used the room. Through the analysis and its results it was made possible to diagnose the main ergonomic problems of the present computer laboratory and to make new directions to solve such problems.
\end{abstract}

Keywords: computer laboratory; ergonomics; health in workspace. 


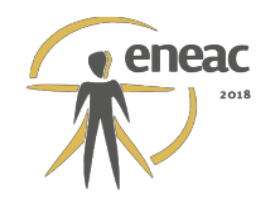

\section{INTRODUÇÃO}

A ergonomia é um importante instrumento de estudo, sendo relevante para o devido conforto do ser humano em seu ambiente de trabalho. Para lida (2005), a ergonomia é o estudo da adaptação do trabalho ao homem fisicamente e quanto à organização do trabalho. Dessa forma, é de suma importância que o arquiteto e urbanista aprenda sobre esse campo de conhecimento, para um melhor entendimento dos problemas existentes entre os trabalhadores no dia-a-dia em seus respectivos ambientes de trabalho, seja em um escritório, um salão de beleza, em salas de aula, laboratórios, etc. para que se possa melhor atender a essas diferentes demandas e problemáticas do trabalho, buscando assim resolver os problemas existentes e melhorar o cotidiano através de técnicas e adaptação dos elementos desses profissionais.

Partindo desse entendimento, o trabalho proposto tem como objetivo a análise ergonômica de um ambiente escolhido com o objetivo de compreender as problemáticas existentes no local, e a partir disso, propor soluções para o devido ambiente, buscando assim o conforto ergonômico dos que ali utilizam. O espaço escolhido foi o Laboratório de Informática, localizado no Campuslar da Universidade Federal de Sergipe (UFS) em Laranjeiras (SE). A motivação da escolha se deu pelo uso intenso desse espaço, como também pela recente troca das cadeiras estofadas por cadeiras de refeitório. As reclamações dos alunos quanto ao conforto das novas cadeiras são frequentes, contestações geralmente relacionadas ao fato da cadeira - por ser metálica - ficar muito gelada devido ao ar-condicionado e não ser confortável para usos prolongados; muitos também consideram o ambiente como não convidativo para se permanecer por um longo período de tempo, além do entendimento de que ali não havia um ambiente de trabalho e estudo que proporcionasse o devido conforto aos usuários do local, sejam eles professores ou estudantes, embora este seja um ambiente diariamente e amplamente utilizado para aula em todos os períodos letivos além de ser usufruído frequentemente pelos discentes.

\section{O AMBIENTE DO LABORATÓRIO DE INFORMÁTICA}

O ambiente escolhido fica localizado no Campus da UFS, em Laranjeiras (SE), funciona como sala de aula e fica no $1^{\circ}$ pavimento da Universidade, sendo este o principal laboratório utilizado. Possui apenas uma entrada, e janela apenas em uma das paredes.

Conta com uma área de aproximadamente $47,6 \mathrm{~m}^{2}$, constando com 4 mesas para os computadores dos alunos, sendo 3 delas constando com 3 computadores e cerca de 5 lugares em cada mesa, e 1 mesa com 4 computadores e com 6 lugares, e ainda com 1 mesa e 1 armário para o professor, localizado na frente da sala, conforme ilustrado nas figuras 1 e 2 .

Figuras 1: Vista da frente da sala

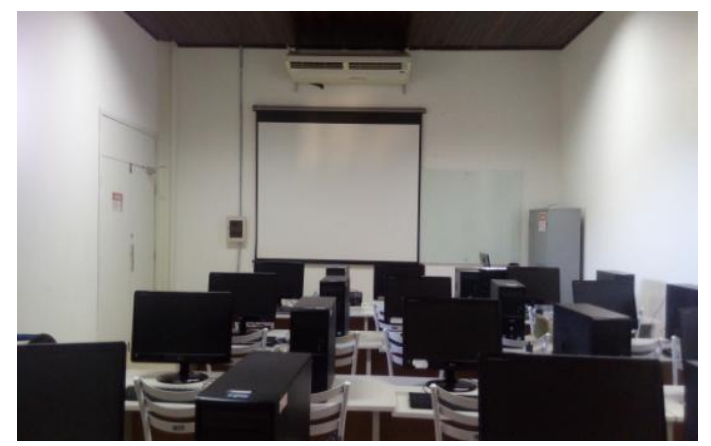

Fonte: Autores, 2017. 


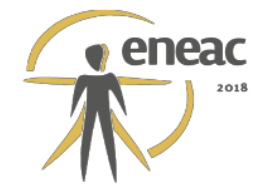

Figuras 2: Planta Baixa do laboratório

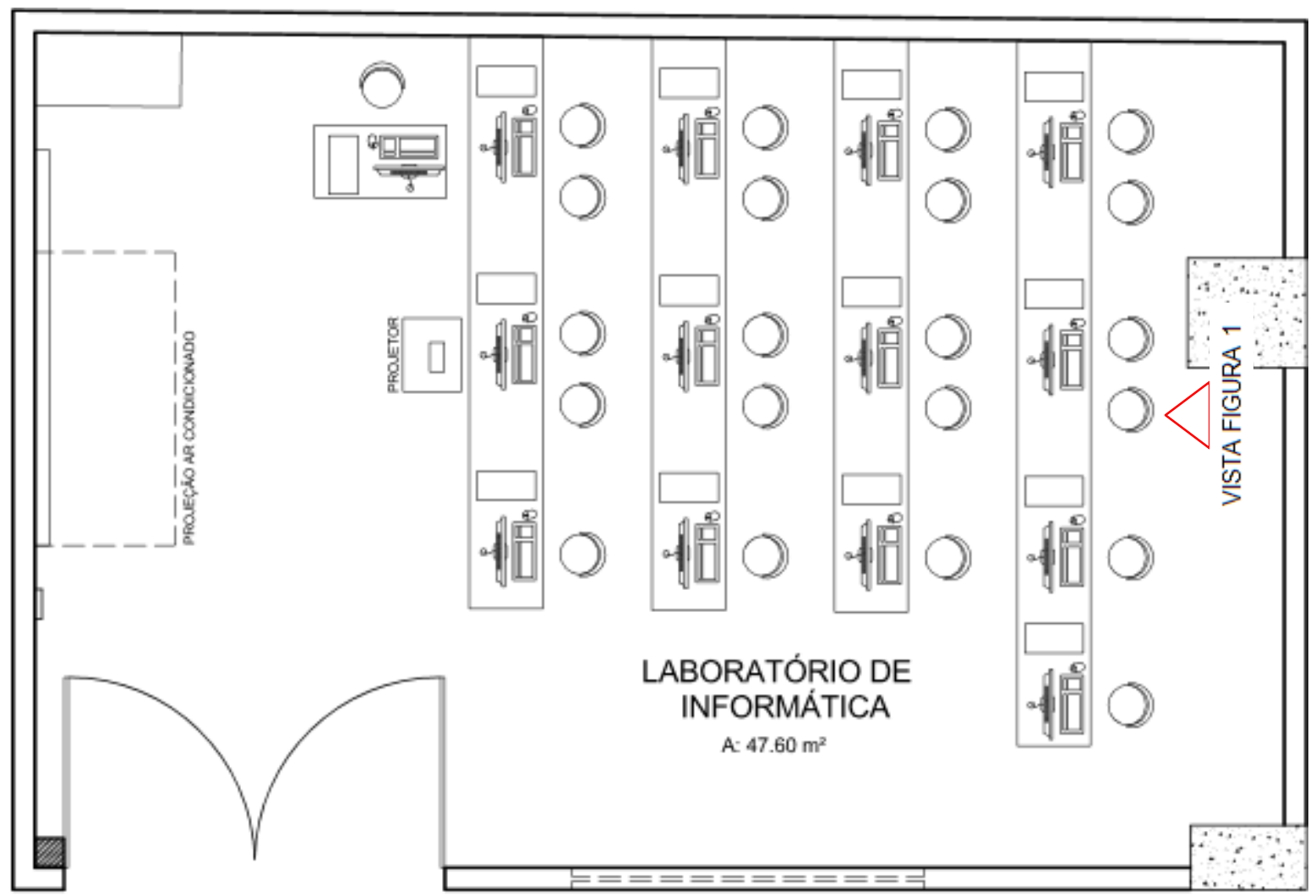

CIRCULAÇÃO

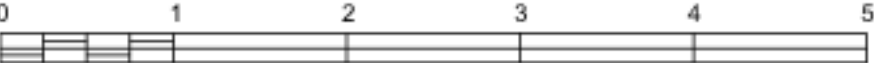

Fonte: Autores, 2017

\section{METODOLOGIA}

A partir dessa escolha, partiu-se para a análise do ambiente a partir de visitas técnicas ao local, retirando as dimensões da sala, bem como com aparelhos que medissem os níveis de iluminância e de ruídos no local. Para o estudo do ambiente em questão, levou-se em conta a Análise Ergonômica do Trabalho (AET), servindo esta como base para o entendimento do que deveria ser realizado, a qual, segundo lida (2005) visa diagnosticar e corrigir situações reais de trabalho. Esse método é dividido em cinco etapas, são elas a análise da demanda; análise da tarefa; análise da atividade; diagnóstico e recomendações. (Guerín et al., 2001).

A primeira etapa trata-se da análise da demanda, ou seja, da descrição de uma situação problema que justifica a necessidade de uma AET (lida, 2005). A respeito deste tópico, percebeu-se a necessidade de estudo do laboratório de informática principalmente pela precariedade do mobiliário existente, em particular as cadeiras utilizadas, alvos frequentes de reclamação dos estudantes; a partir disso, realizaram-se visitas ao laboratório com o intuito de verificar se a problemática era de fato existente. Fez-se também uma avaliação acerca das condições do ambiente, através dos aparelhos, Decibelímetro digital datalogger 


\title{
(x) $^{\text {reace }}$
}

modelo DT-8852 e o Luxímetro Tenmars modelo TM-202, com o objetivo de melhor compreender o ambiente.

A segunda etapa, análise da tarefa diz respeito aos objetivos que os trabalhadores devem desempenhar. (lida, 2005). Esta etapa pode se aplicar pelas funções exercidas pelos estudantes na sala, pois estes estão em todo tempo utilizando programas no computador e realizando trabalhos no mesmo.

A terceira etapa é a análise da atividade, referindo-se ao comportamento apresentado pelo trabalhador no cumprimento de uma determinada tarefa, podendo esta atividade ser influenciada por fatores externos ou internos, segundo lida (2005). Esta etapa pode ser aplicada aos estudantes que utilizam o laboratório para se entender seu comportamento na sala; fez-se uma visita ao laboratório em dia de aula, como também foi realizada a aplicação de um questionário virtual com o intuito de entender melhor as problemáticas existentes pela visão dos que utilizam o local. Fez-se ainda a aplicação da metodologia do Poema dos Desejos (Wish Poems) com alguns alunos. Esta metodologia é uma aplicação desenvolvida por Henry Sanoff. Segundo Sanoff (2001):

\begin{abstract}
“Um poema dos desejos é uma abordagem que encoraja estudantes, professores e pais a imaginar sua escola dos sonhos através de um processo aberto mas ainda assim estruturado. Poemas dos desejos são consideravelmente mais efetivos que estabelecer objetivos, particularmente se a intenção é manter o pensamento global e exploratório. Diferente de poemas tradicionais que rimam, o poema dos desejos é espontâneo e permite um fluxo livre de informação. O processo consiste em um grupo de estabelecimentos compostos de respostas à frase "EU QUERIA QUE MINHA ESCOLA..." (Sanoff, 2001, tradução dos autores)
\end{abstract}

Percebeu-se que a aplicação desse método seria de ajuda para uma melhor compreensão do espaço analisado, sobretudo por compreender uma forma de questionário mais livre e intuitiva. A aplicação se deu em dois momentos distintos em que havia aula no laboratório em questão; como não foi imposto a obrigação de responder as perguntas previstas, o método acabou sendo respondido por somente seis estudantes, servindo apenas de cunho experimental para a análise do ambiente.

A quarta etapa trata-se da formulação do diagnóstico, sendo este possível após o entendimento do método em conjunto com a análise da problemática existente, as percepções obtidas nas visitas ao ambiente, resultados das medições com os aparelhos, resultados do questionário e do Poema dos Desejos.

A última etapa são as recomendações ergonômicas, ou seja, sugestões e providências para se resolver os problemas diagnosticados (lida, 2005). No estudo em questão, através da obtenção de todas essas informações, chegou-se aos resultados obtidos, permitindo dessa forma, um melhor entendimento das problemáticas existentes no devido ambiente de estudo, bem como, possibilitando que mudanças sejam feitas para o melhor atendimento das necessidades e precariedades existentes no local proposto.

\section{RESULTADOS E DIAGNÓSTICOS}

\subsection{O Questionário}

O questionário virtual lançado obteve quarenta e uma respostas, sendo estas de estudantes que atualmente tem aulas na sala, ou que já tiveram aula no local em períodos anteriores. 


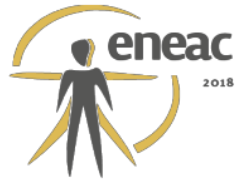

As perguntas realizadas foram um total de doze, onde onze delas foram perguntas fechadas (com múltipla escolha) sobre a frequência do uso da sala, à sua acústica, conforto térmico e luminoso, bem como relacionadas ao mobiliário e as cores do ambiente, e uma pergunta aberta onde os respondentes poderiam dizer se haviam sentido dores ocasionadas durante o uso do laboratório.

A partir de então, foram obtidos gráficos para a análise dos dados, os quais representam as perguntas realizadas bem como suas respectivas alternativas. Tal formulário foi aplicado após o poema dos desejos para que as respostas deste último não fossem influenciadas pelo questionário.

As primeiras perguntas foram quanto à freqüência de utilização do laboratório pelos alunos e quanto à temperatura térmica da sala. $54 \%$ dos entrevistados utilizam a sala somente quando tem aula, enquanto $39 \%$ utilizam também, ou somente, em momentos de estudo. 0 grande percentual de alunos que não a utilizam de forma extracurricular apesar de sua disponibilidade pode indicar desconforto quanto ao espaço. Ainda a maioria $(58,5 \%)$, considera a temperatura agradável, enquanto que $41,4 \%$ consideram desagradável de alguma maneira. Apesar de obtidos resultados positivos, o número de insatisfeitos é considerável.

Quanto à questão da acústica, se percebeu que a grande maioria $(66,9 \%)$ não consegue ouvir ou tem dificuldade em ouvir o professor dando aula, enquanto que $34,1 \%$ afirmam conseguir ouvir totalmente. Devido ao resultado, assimilado à pergunta de número 5 sobre a visualização de projeção do professor, observa-se que, provavelmente, os únicos pontos onde a acústica se faz satisfatória são nos computadores dispostos na primeira mesa da sala, já que $63,4 \%$ dos entrevistados não conseguem ter uma boa visualização do quadro/projeção ou do professor, podendo este ser um problema tanto da reflexão da lona de projeção, do reflexo no quadro e da precariedade da iluminação.

A pergunta relacionada à aparência da sala pode-se referir tanto à cor do ambiente, quanto ao tamanho ou organização da sala, sendo assim, 46,3\% considera o ambiente agradável de alguma forma, enquanto que 53,7\% o consideram desagradável de alguma maneira.

Já relacionado aos problemas de ruídos externos, 60,9\% percebem ruídos e são atrapalhados por eles de alguma forma, enquanto que outros $39 \%$ não escutam ou não se sentem atrapalhados com ruídos. Apresenta-se aqui um considerável número de alunos que não se sentem atrapalhados, porém um número ainda maior de incomodados; tal resultado pode levar a crer acerca de uma necessidade quanto a um isolamento acústico da sala, já que esta fica ao lado de um corredor de considerável circulação diária.

Sobre os resultados quanto ao mobiliário (que é reclamação mais recorrente dos alunos) constatou-se que a maioria considera o mobiliário não adequado (51,2\%), e os que acreditam ser razoável ou que poderia melhorar somam 48,8\%. Estes percentuais compreendem 100\%; sendo assim, nenhuma resposta obtida considera o mobiliário da sala devidamente adequado, como visto na Figura 3.

Figura 3: O mobiliário é adequado para as funções exercidas?

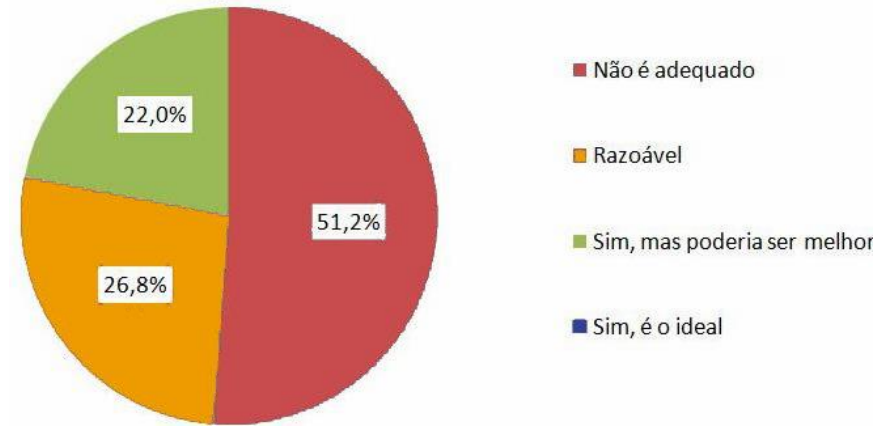




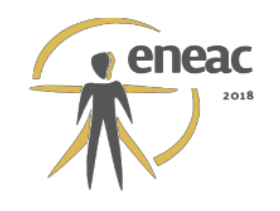

Quanto ao questionamento sobre a iluminação do laboratório de informática, nota-se, através da Figura 4, que apenas $4,8 \%$ das respostas consideram o ambiente bem iluminado, enquanto outros $93,2 \%$ o consideram inadequado de alguma forma.

\section{Figura 4: A iluminação é adequada para as atividades que você desempenha no laboratório?}

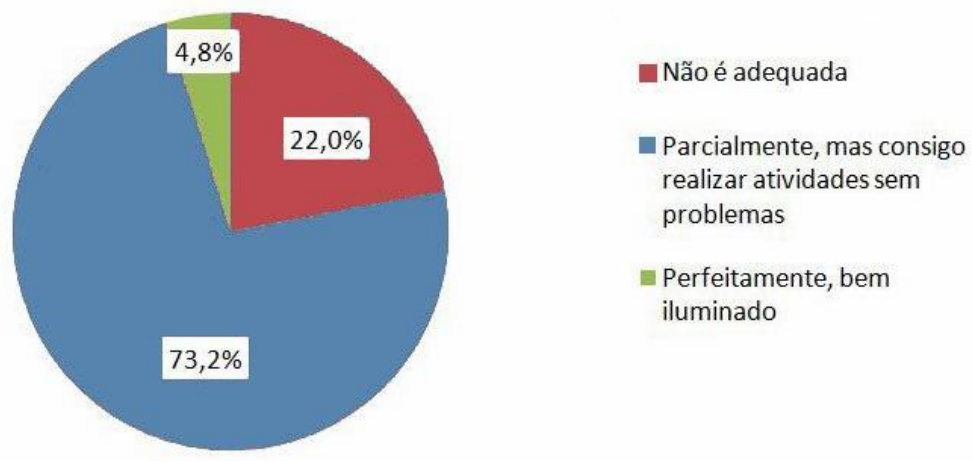

Fonte: Autores, 2017

Quanto a influência de luz solar na sala, percebida em análise pela má posição da janela, sendo a mesma vedada apenas de forma parcial, apenas $26,8 \%$ consideram que a claridade incomoda de alguma forma, enquanto que $73,2 \%$ não se sentem incomodados ou não percebem essa influência de luz externa.

Outra pergunta foi sobre como os alunos consideram a cor atual do laboratório, e saber se os alunos tem entendimento de qual cor seria a ideal. Atualmente a sala é de cor branca, apontado por $12,2 \%$ dos respondentes como a cor ideal para o espaço; outros $53,7 \%$ marcaram tons pastéis como ideal, enquanto que $34,1 \%$ apontaram que preferem cores frias; é importante dizer que essa pergunta foi aplicada com as imagens dos tons ou cores sendo visíveis, apresentados em imagens, possibilitando que os respondentes pudessem compreender adequadamente qual tipo de cor eles consideram adequada.

A pergunta de número 10 (Figura 5) foi uma das mais relevantes, pois foi realizada de forma aberta, possibilitando que os respondentes pudessem escrever se já sentiram dores ao utilizar os equipamentos do laboratório e em qual parte do corpo. Nota-se que 29,6\% relatam que nunca sentiram dores, enquanto que $70,4 \%$ afirmam já terem sentido dor em alguma parte do corpo, sendo a maioria destas respostas dores na coluna $(39,58 \%)$, podendo estar sendo ocasionada por má postura e pela precariedade da cadeira; em seguida aparece dor no punho $(8,33 \%)$, no braço $(2,08 \%)$ e no ombro $(2,08 \%)$, somando estes últimos três 12,49\%; essas dores podem estar sendo ocasionadas pela altura inadequada do mouse ou do teclado. Ainda $6,25 \%$ relataram dores nos glúteos, podendo esta ser ocasionada pelo mau conforto da cadeira do laboratório; outros 6,25\% relataram problemas na nuca, que pode ser ocasionada pela falta de regulagem da altura do monitor ou pela baixa altura da cadeira que não permite regulagem de altura; $2,08 \%$ indicaram dores no joelho, que pode também estar relacionada à falta de regulagem da cadeira. Outros $4,16 \%$ indicaram desconforto de alguma forma, contudo não indicaram onde sentiram esse desconforto. 


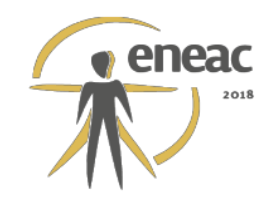

Figura 5: Você já sentiu dores ao utilizar os equipamentos do laboratório? Se sim, em qual parte do corpo?

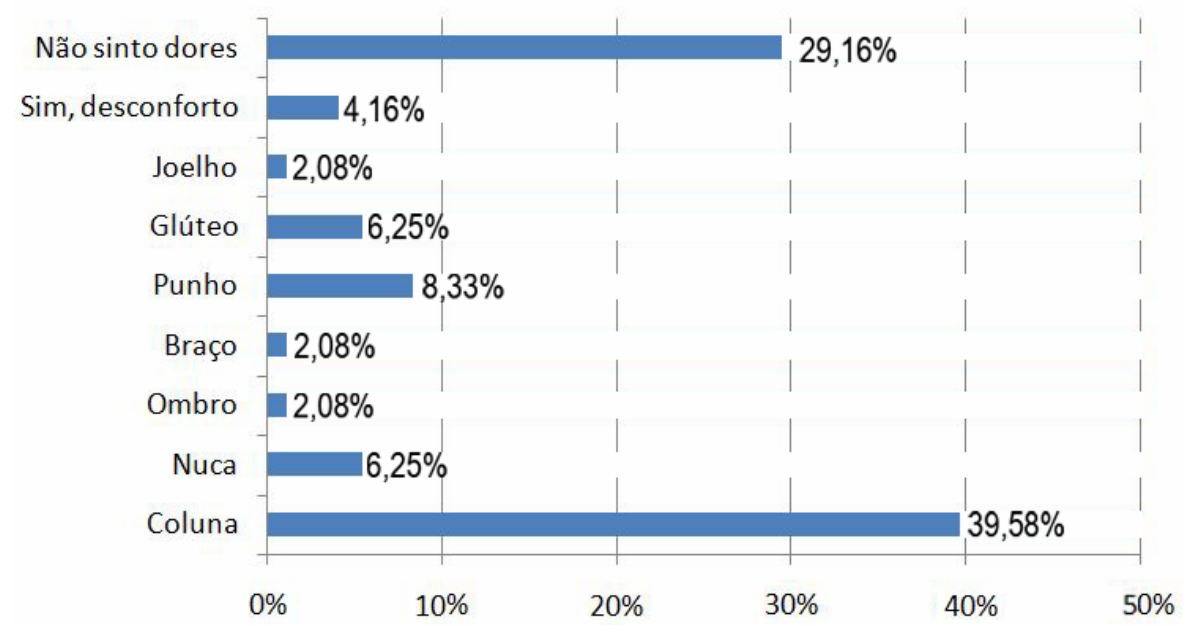

Fonte: Autores, 2017

A pergunta de número 12 (Figura 6), por sua vez, foi feita com a opção de imagens (Figura 7), para que os respondentes pudessem visualizar qual tipo de cadeira eles consideram ideal para o laboratório. Sendo a opção 1 a cadeira existente atualmente no laboratório, percebe-se que esta não obteve nenhuma resposta; a opção 2 referia-se a uma cadeira acolchoada sem braço e sem regulagem de altura, sendo respondida por $22 \%$ como a cadeira ideal; as opções 3 e 4 referiam-se a cadeiras que já estiveram no laboratório e estão presentes nas salas de aula do Campuslar, mas assim como a opção 1 também não obtiveram nenhuma resposta; a opção 5 referia-se a uma cadeira acolchoada, com braços e que permite a regulagem de altura, a qual grande maioria (78\%) a consideraram como a ideal.

Figura 6: Sobre as cadeiras do laboratório, qual você considera mais adequada (confortável) para a utilização desse espaço?

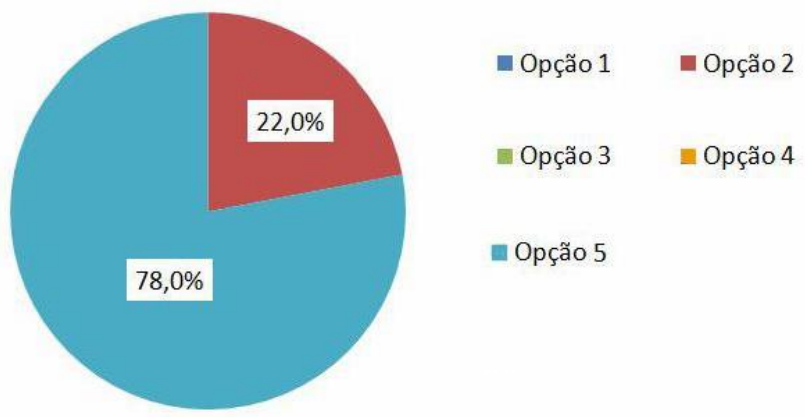

Fonte: Autores, 2017

Figura 7: Opções de cadeiras colocadas no questionário. Opções de 1 à 5, da esquerda para a direita.
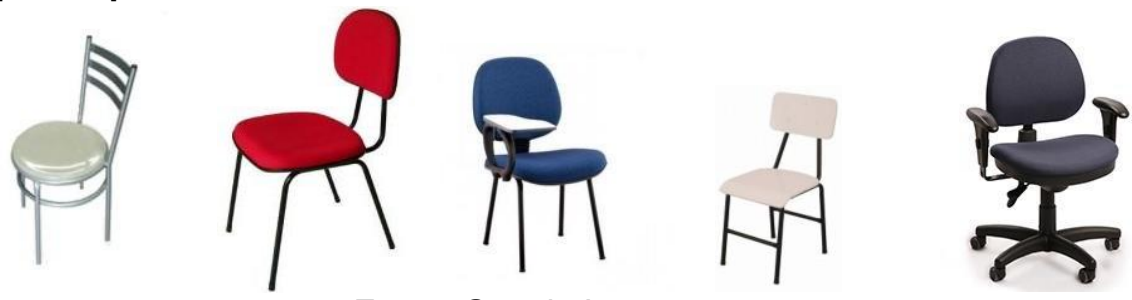

Fonte: Google Imagens, 2017 


\subsection{O Poema dos Desejos}

A metodologia do poema dos desejos (Wish Poems), foi adotada devido a uma maior liberdade de resposta que oferece para aqueles que são submetidos a ela, permitindo assim que os alunos pudessem se expressar de forma livre e despreocupada quanto a respostas corretas, podendo utilizar tanto da escrita como de desenhos. Foram realizadas duas simples perguntas, uma acerca de como os estudantes se sentem estando no laboratório da maneira que é hoje e outra sobre como eles gostariam que este espaço fosse. Foram obtidas poucas respostas devido à sua aplicação de caráter experimental, na qual apenas buscou-se confirmar as reclamações ouvidas acerca do espaço, sem forçar os alunos a participar.

Dessa forma, seis alunos participaram dessa aplicação; as respostas quanto à maneira que se sentem no laboratório são semelhantes, dos quais cinco reclamam acerca do mobiliário existente - surgem também pontos como iluminação precária, falta de espaço por aluno e temperatura e cores desagradáveis. As respostas para a pergunta de como esses alunos gostariam que a sala fosse, no geral, são simples, a maioria delas apenas se opondo aos pontos negativos apresentados na primeira resposta. (Figura 8),

Figura 8: Respostas ao Poema dos Desejos
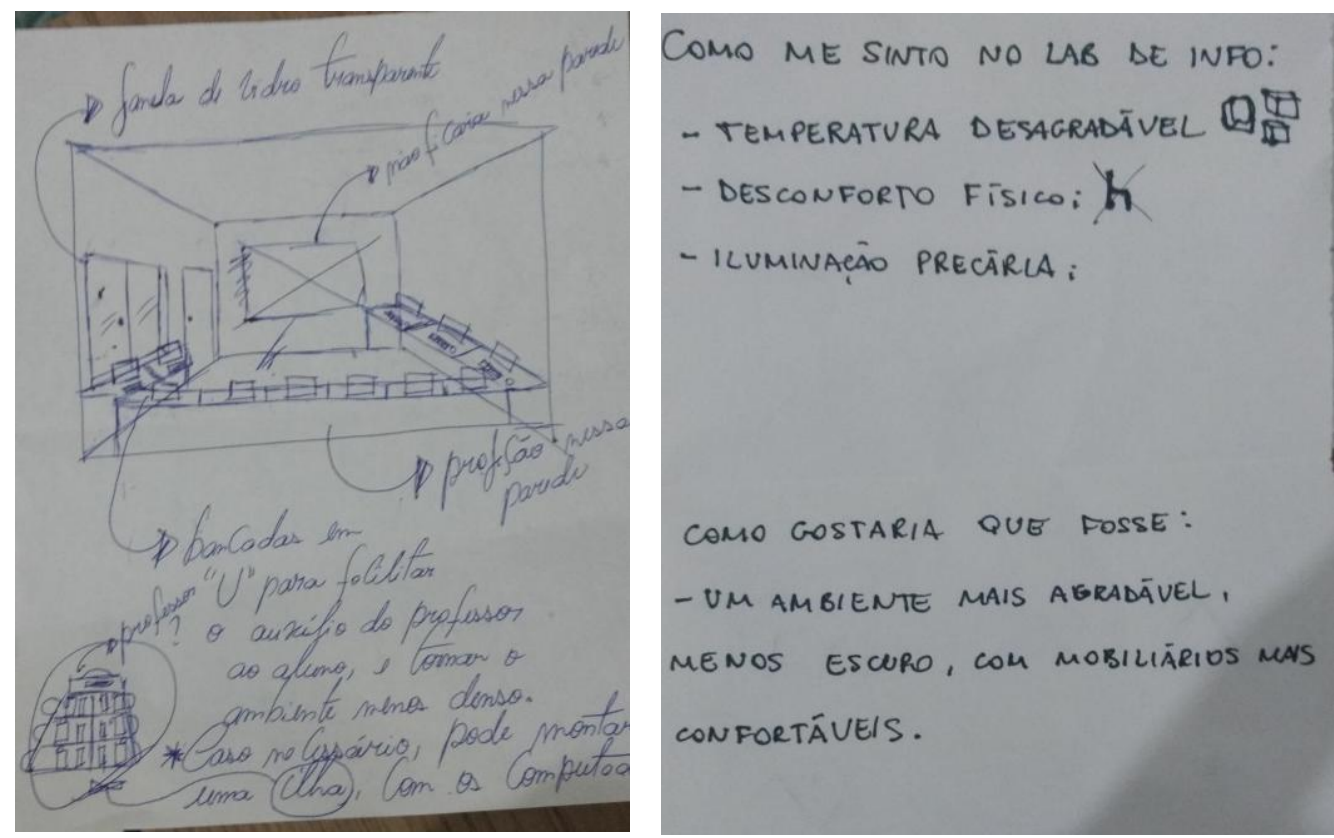

Fonte: Autores, 2017

\subsection{As medições}

Foram realizadas medições com a sala vazia, utilizando os aparelhos de decibelímetro (Datalogger modelo DT-8852) e de luxímetro (Tenmars modelo TM-202), que medem os níveis de som e de luz no ambiente, respectivamente. Os resultados obtidos foram pautados segundo a NBR 5413 (ABNT - 1992), que apesar de ter sido cancelada pela ABNT em 2013 e substituída pela norma NBR ISO/CIE 8995-1 (ABNT - 2013), continua válida para os valores de iluminância. 
Pela análise dos resultados constatou-se que os índices das medições ficaram muito aquém dos índices de 200 (lux) recomendados pela norma NBR 5413 (ABNT - 1992). Os pontos mais próximos das lâmpadas são os que apresentam os maiores índices, com 89,3 (lux) e 73,4 (lux). Já os pontos que ficam ao fundo da sala e próximos ao pilar apresentam os índices mais baixos com 53,5 (lux) e 43,3 (lux), mesmo estes estando próximos aos pontos de luz, tem sua iluminância prejudicada pelo pilar, que acaba causando sombra.

Quanto aos níveis de ruído, a figura 9 e a Tabela 1 representam os pontos de medição com o aparelho que afere os ruídos no ambiente em $\mathrm{dB}(\mathrm{A})$, e os resultados obtidos pela medição, bem como o índice recomendado pela NBR 10152 (ABNT - 1987).

Figura 9: Pontos de medição do aparelho de Decibelímetro.

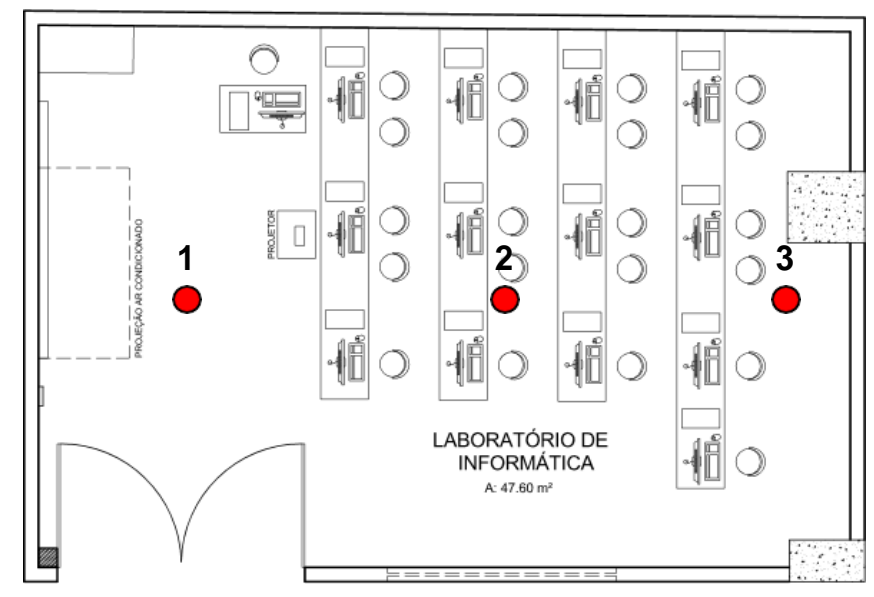

Fonte: Autores, 2017

Tabela 1: Resultado das medições de ruído nos pontos do laboratório e o índice recomendado pela NBR.

\begin{tabular}{|c|c|c|}
\hline Pontos & $\begin{array}{c}\text { MEDIÇÕES } \\
\text { (dBA) }\end{array}$ & $\begin{array}{c}\text { NBR 10152 } \\
\text { (dBA) }\end{array}$ \\
\hline $\begin{array}{c}1 \text { (frente do } \\
\text { laboratório) }\end{array}$ & 67,2 & $40-50$ \\
\hline $\begin{array}{l}\text { ( centro do } \\
\text { laboratório) }\end{array}$ & 65,15 & $40-50$ \\
\hline $\begin{array}{l}\text { 3 (fundo do } \\
\text { laboratório) }\end{array}$ & 63,85 & $40-50$ \\
\hline
\end{tabular}

Fonte: Autores, 2017 


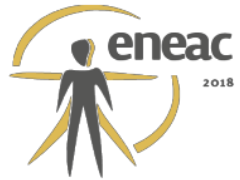

Nota-se que os índices recomendados pela NBR 10152 (ABNT - 1987) estão abaixo do resultado das medições,pode-se aferir que o resultado apresenta índices mais altos na frente da sala por conta da presença do ar-condicionado que se encontra em cima do quadro, as medições foram realizadas com o ar-condicionado ligado. Outro fator que contribui com o alto nível de ruído são os ruídos externos, pois se percebe que a sala não possui as devidas vedações das esquadrias, nem isolamento acústico nas paredes e forro em madeira, o que contribui para a presença desses ruídos.

É importante frisar que ambas as medições, de iluminância e de ruídos, foram realizadas fora dos horários de aula, podendo estes ser alterados pela presença de alunos no local, entende-se que os índices dos níveis de ruído em horários de aula provavelmente são maiores pelo uso do computador, bem como pelas conversas existentes em aula, enquanto que os índices dos níveis de iluminância não sofreriam nenhuma mudança brusca.

\subsection{Diagnóstico}

A partir do que foi analisado e exposto acima é possível identificar que os principais problemas do Laboratório de Informática, no que diz respeito à Ergonomia do trabalho são principalmente acerca do mobiliário, visto que as cadeiras (Figura 10) são inapropriadas para as funções desempenhadas na sala de aula, bem como para se passar muito tempo nas mesmas, podendo provocar diversas dores relatadas pelos estudantes no questionário.

\section{Figura 10: Cadeira utilizada no laboratório de informática}

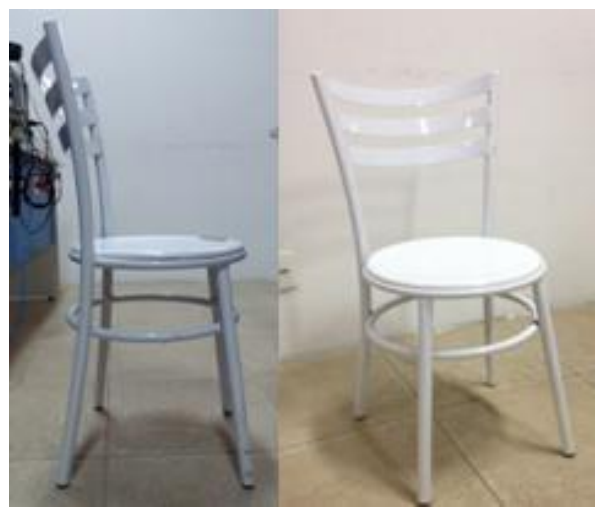

Fonte: Autores, 2017

Outro problema diagnosticado foi quanto aos ruídos no laboratório quando este está em função de sala de aula, que atrapalham a total compreensão da explicação do professor. Há ainda a problemática da iluminação, sendo constatada insuficiente para um ambiente de sala de aula, prejudicando dessa forma a perfeita visualização do quadro, ou da projeção nas aulas teóricas que também ocorrem no laboratório. Quanto à problemática da aparência da sala, se tem a parede branca que pode causar fadiga ocular com um tempo excessivo de exposição que segundo Carneiro (2012), ocasiona em problemas de cansaço e concentração dos alunos.

\section{RECOMENDAÇÕES}

Os resultados obtidos através da análise ergonômica e resumidos no diagnóstico acima mostram uma série de fatores que se melhorados podem aumentar o desempenho e eficiência na realização das atividades exercidas no laboratório, tanto para os estudantes 


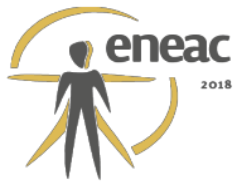

quanto para o professor. Dessa forma serão sugeridas melhorias à curto prazo e à longo prazo que podem ser aplicadas.

Como medida à curto prazo e extremamente necessária, se recomenda a troca das cadeiras modelo refeitório do laboratório por cadeiras que, segundo MOTTA (2009), devem ser estofadas com tecido que permita a transpiração, tenham a altura regulável, tenham apoio para o dorso em uma forma que acompanhe a curvatura da coluna e seja giratória. (Figura 11).

Figura 11: Cadeira ideal para o laboratório de informática

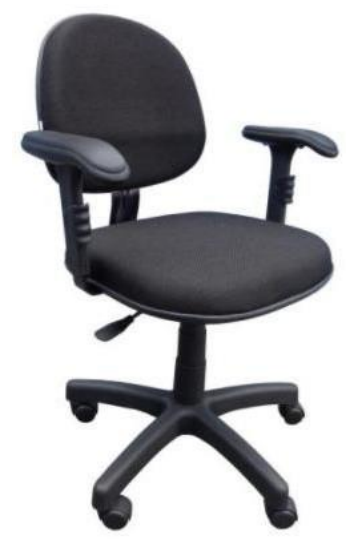

Fonte: http://www.metromoveis.com.br/cadeiras-para-escritorio-curitiba.htm. Acesso em Janeiro, 2018.

Outra alteração importante seria aumentar a potência das lâmpadas e os pontos de luz para melhor distribuir a iluminação pela sala, especialmente devido ao forro de madeira que absorve parte da luz. As luminárias por sua vez, se mostram adequadas pois possuem uma superfície espelhada que reflete a luz de volta para o ambiente. Seria ideal ainda que os vidros da janela fossem devidamente cobertos com material opaco.

Como dito anteriormente, a cor branca não é estimulante para salas de aula e por esta razão, recomenda-se que as paredes do laboratório sejam pintadas em tons pastéis ou ainda em combinações que estimulem a criatividade e a permanência do usuário na sala de aula em bem-estar. Ainda quanto às medidas de curto prazo, além das descritas acima, propõe-se a mudança do layout da sala permitindo computadores fiquem mais bem distribuídos e permita uma visualização homogênea de todos os cantos do laboratório. Entretanto, as dimensões atuais do laboratório não permitem que tais alterações sejam feitas, especialmente por este ser estreito.

Quanto à medidas à longo prazo, recomenda-se a aplicação de isolantes acústicos que diminuam a interferência de ruídos externos, tanto nas paredes como nas esquadrias e teto, bem como a troca do aparelho de ar condicionado por outro mais silencioso. Por fim, recomenda-se que a projeção seja posicionada de forma mais elevada, isso implicaria na mudança de posição, ou elevação do ar-condicionado, que se encontra presente na mesma parede do rolo de projeção, impedindo que a projeção seja mais alta. Ainda, aconselha-se o projetor ser colocado de maneira fixa no teto, facilitando assim a projeção.

\section{CONSIDERAÇÕES FINAIS}

A análise ergonômica do laboratório de informática do Campuslar da Universidade Federal de Sergipe traz uma reflexão sobre a existência do curso de Arquitetura e Urbanismo no Campus estudado, já que este é a "casa" dos arquitetos, um espaço de referência para 


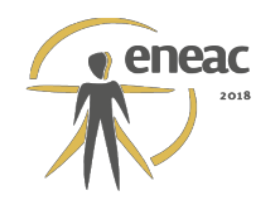

futuros profissionais da área e deveria trazer contribuições para a sua estrutura, mesmo em quesitos simples como layout e qualidade da iluminação nos ambientes.

Entretanto, como diagnosticado na análise ergonômica e na metodologia, especialmente com o Poema dos Desejos, percebe-se que a presença do curso de Arquitetura no Campus não tem promovido tais melhorias. Essas adequações dos espaços para otimizar as condições de trabalho e aumentar a produtividade poderiam até ser objeto de estudo das disciplinas do curso de Arquitetura, pois além de grande importância seria visto na prática a diferença que um ambiente bem projetado traz para o desempenho do profissional e estudante, além de como os espaços e sua organização influenciam no desempenho dos que utilizam o espaço.

Dessa forma, constata-se um paradoxo existente no campus da Universidade que encaixa com a expressão "Santo de casa não faz milagre", visto que, apesar de abrigar um curso que está totalmente ligado à ergonomia, não é visível nenhum resultado dentro do campo da mesma.

\section{REFERÊNCIAS BIBLIOGRÁFICAS}

Associação brasileira de normas técnicas - ABNT. NBR 10152 - Nível de ruído para conforto acústico, 2000. Brasil.

Associação brasileira de normas técnicas - ABNT. NBR 5413 - Iluminância de Interiores, 1992. Brasil.

CARNEIRO, Rosângela M de Souza. A Cor nas salas de aula do Ensino Médio: Recomendações com base em estudos de escolas em Florianópolis. Dissertação (mestrado) - Universidade Federal de Santa Catarina, Centro Tecnológico. Programa de Pós-Graduação em Arquitetura e Urbanismo. Florianópolis,2012.

IIDA, Itiro. Ergonomia: Projeto e Produção. São Paulo: Edgard Blucher, 2005..

MACHADO, E. S., AZEVEDO, G.A.N., ABDALLA, G.F. A Importância do Olhar dos Usuários em Ambientes da Arquitetura Hospitalar: uma aplicação do Poema dos Desejos. 2011. In: Anais do 2o. Simpósio Brasileiro de Qualidade do Projeto no Ambiente Construído X Workshop Brasileiro de Gestão do Processo de Projeto na Construção de Edifícios, Rio de Janeiro - RJ, Brasil. [Internet] Disponível em: <http://www.iau.usp.br/ocs/index.php/sbqp2011/sbqp2011/paper/viewFile/292/194>. Acesso em:Dez. 2017

MOTTA, F. V. Avaliação Ergonômica De Postos De Trabalho No Setor De Pré- Impressão De Uma Indústria Gráfica. 2009. [Internet] Disponível em: <http://www.ufj.br/ep/files/2014/07/2009_1_Fabricio.pdf>. Acesso em: Dez. 2017

SANOFF, Henry. School Building Assessment Methods. Washington: National Clearinghouse for Educational Facilities, 2001. [Internet] Disponível em <http://www4.ncsu.edu/ sanoff/schooldesign/schoolassess.pdf> . Acesso em dez.2017. 